\title{
Validating various measures to accelerate the static gravimetric
}

\section{sorption isotherm determination}

\author{
Chi Feng ${ }^{1,2^{*}}$, Hans Janssen ${ }^{2}$, Chenchen $\mathrm{Wu}^{1}$, Ya Feng $^{3}$, Qinglin Meng ${ }^{1}$
}

1. Building Environment and Energy Laboratory (BEEL), State Key Laboratory of Subtropical Building Science, South China University of Technology, Wushan, Guangzhou, P.R. China 510641

2. Building Physics Section, Department of Civil Engineering, KU Leuven, Kasteelpark Arenberg 40, Leuven, Belgium 3001

3. China Southwest Architectural Design and Research Institute Corp. LTD, Chengdu, P.R. China 610041

*: Corresponding author, Building Physics Section, Department of Civil Engineering, KU Leuven, Kasteelpark Arenberg 40, Leuven, Belgium 3001; fengchi860602@gmail.com; +32 488927850

\begin{abstract}
The sorption isotherm is one of the most important hygrothermal properties of porous building materials, and is usually determined by the static gravimetric test. Typically the static gravimetric test takes weeks or months to complete, thus various measures are adopted to improve the test efficiency. Unfortunately, not all these measures have been validated specifically. This paper aims at validating several widely accepted measures to speed up the static gravimetric test on autoclaved aerated concrete at $25^{\circ} \mathrm{C}$. Experimental results show that oven drying at $70^{\circ} \mathrm{C}$ gives nearly identical dry mass as desiccant drying at room temperature does, but is much faster than the desiccant method and avoids potential risks at $105^{\circ} \mathrm{C}$. Moreover, large and small samples provide almost the same equilibrium moisture content, while small samples shorten test time obviously. In addition, as long as one-way adsorption process is kept without reverse, the effect of intermediate relative humidity levels on the equilibrium moisture content is negligible, supporting the method of exposing different samples to different $\mathrm{RH}$ levels simultaneously. Last but not least, a new mathematical model is introduced to fit the sorption curves. It works better than the Oswin, Henderson, Caurie, GAB, Hansen and Peleg models do.
\end{abstract}

Keywords: sorption isotherm; static gravimetric test; drying method; sample size; intermediate RH level; best-fitting model

\section{Highlights}

- Measures to accelerate static gravimetric tests on sorption isotherms are examined.

- Oven drying at $70^{\circ} \mathrm{C}$ is the best drying method.

- Small samples are better than large ones in efficiency, and are the same reliable.

- Intermediate RH levels have no significant influence on one-way adsorption tests.

- Our new model is the best in fitting sorption isotherms. 
Postprint: Feng C, Janssen H, Wu C, Feng Y, Meng Q. 2013. Validating various measures to accelerate the static gravimetric sorption isotherm determination, Building and Environment, 69:64-71.

doi: 10.1016/j.buildenv.2013.08.005

\section{Introduction}

\subsection{Background}

Moisture storage and transport in porous media is of great importance in various areas, such as in food processing [1, 2], energy and power engineering [3-5], soil science [6, 7], as well as in environmental protection [8-10]. When it comes to building physics, a good insight in and adequate control of moisture transfer processes allow us to prolong the service life of building components [11-13], to reduce the energy consumption by HVAC systems [14-16], to mitigate indoor temperature and humidity fluctuations [17-19], as well as to improve indoor air quality [20-22].

In building physics, the sorption isotherm is often used to describe the moisture storage of building materials in the hygroscopic range: it describes a material's equilibrium moisture content (EMC) when exposed to a given relative humidity $(\mathrm{RH})$. Moreover, many other hygrothermal properties such as thermal conductivity, water vapor permeability and moisture diffusivity - depend heavily on materials' moisture content, and are therefore closely related to the sorption isotherm [23-26]. Consequently, the sorption isotherm is indispensable for the modeling of materials' hygrothermal properties and the analysis of buildings' heat, air and moisture (HAM) performances [27-30].

Sorption isotherms of porous building materials have been extensively tested throughout the world. Many (inter)national projects - such as EC HAMSTAD [23], IEA Annex 24 [24] and ASHRAE Research Project 1018-RP [31] - have been executed, and relatively complete databases of hygrothermal properties are available for a lot of common building materials. Usually the static gravimetric method is applied for the determination of sorption isotherms. The basic concept of this method is to expose test samples to rising/decreasing RH sequences. By comparing the initial dry mass and the equilibrium wet mass at each RH level, the EMCs at different RHs can be obtained. Many standards - such as ISO 12571 [32] and ASTM C1498 [33] - provide detailed descriptions for the test procedure.

The static gravimetric method is simple and reliable. However, it usually takes several weeks or even months to complete the drying and sorption processes involved [34-37]. To improve experimental efficiency, many measures are often taken, with respect to drying methods, sample sizes, RH levels, test temperature... These measures may have significant influence on the test results but have unfortunately received inadequate attention. Thus the reliability and applicability of the currently available data are open to discussion.

\subsection{Existing uncertainties in sorption isotherm measurement}

The dry mass of test samples is of vital significance, as it is the basis for determining and expressing a material's moisture content. When it comes to building materials, two drying methods are commonly used: desiccant drying at room temperature and oven drying at elevated temperature. There is no risk of potential chemical reactions and irreversible structural changes for the desiccant method, thus it is recommended by many researchers as the standard drying method. For instance, Richards observed that different drying methods resulted in different dry mass for 12 materials and recommended desiccant drying at room temperature to avoid the dissipation of volatile content in materials, as well as to minimize chemical reactions and structural changes. He also suggested a maximum temperature of $70^{\circ} \mathrm{C}$ for oven drying [38]. Later Wilkes found that drying conditions had a significant effect on the sorption isotherms of gypsum materials. Desiccant drying at room temperature was also recommended by him for materials with chemically bound water [39]. However, a big problem of the desiccant drying method is that it takes a very long time - usually weeks or months - to completely remove all physically bound water in materials. On the contrary, oven drying at elevated temperature can be completed within days, and is thus far more popular. However, notwithstanding that the oven drying method is widely used throughout the world, the 
Postprint: Feng C, Janssen H, Wu C, Feng Y, Meng Q. 2013. Validating various measures to accelerate the static gravimetric sorption isotherm determination, Building and Environment, 69:64-71.

doi: 10.1016/j.buildenv.2013.08.005

choice of the drying temperature remains inconsistent: it can be either above $100^{\circ} \mathrm{C}$ (usually $105^{\circ} \mathrm{C}$ ) or below $100^{\circ} \mathrm{C}$ (usually $70-80^{\circ} \mathrm{C}$, but at times also $50^{\circ} \mathrm{C}$ ). Peuhkuri studied the influence of drying temperature on the sorption isotherms of 5 different materials, and reported a significant impact. She also argued that not all materials can sustain $105^{\circ} \mathrm{C}$ without impact, given that this is the traditional oven drying temperature [36]. Recently Korpa [40] and Espinosa [41] experimentally analyzed the influence of different drying methods on the sorption isotherms of cement-based materials, and found that drying at elevated temperatures could lead to changes in pore structures. Poyet furthermore pointed out that oven drying at $105^{\circ} \mathrm{C}$ might be too drastic for cement-based materials because the structural changes at this temperature were irreversible [37]. Actually it has been pointed out in the ISO 12570 standard that the choice of oven temperature should be based upon materials' stability to avoid structural changes and chemical reactions [42]. Notwithstanding this guidance, the effect of drying methods and oven temperature on materials' structure and dry mass remains largely unclear, and different scholars chose different drying methods even facing the same material [23, 35, 43]. In general, it is widely accepted that drying methods have noticeable influence on the dry mass and hence on sorption isotherms. However, no consensus has been reached concerning the most reliable and efficient drying method.

Another important reason for the long measurement interval in gravimetric sorption tests is the adoption of large samples (over $10 \mathrm{~g}$, as required by ISO 12571 [32]). To improve the test efficiency, these large samples are sometimes crushed or even powdered. This strategy is very effective [44, 45], but its effect on the EMC is uncertain and only few researchers have looked into the issue. Theoretically, crushing samples may destroy the material's original pore structure, increase open porosity, and thereby exert influence on the EMCs. However, the sorption process in the hygroscopic range is mainly determined by small pores, which are not very vulnerable when cutting or crushing samples. It is therefore entirely possible that sample size does not matter very much. By comparing the sorption isotherms obtained with standard desiccator tests (using large samples, 10-50 g) and with sorption balance (using crushed samples, 50-100 mg), Peuhkuri obtained almost identical curves for some materials but noticeably different curves for several other materials [36]. It is hence still unclear whether large and crushed samples can always provide the same EMC results. As a first step in this direction, the EMCs obtained with large samples (in the $10 \mathrm{~g}$ order-of-magnitude) and small samples (in the $1 \mathrm{~g}$ order-of-magnitude) could be compared, as is discussed in this paper.

One more common strategy for shortening the test time is to expose different samples to different RH levels simultaneously [23, 37, 44-51], rather than putting the same group in sequential RH levels [31, 35, 36, 52]. The uncertainties involved here are twofold. Firstly, using different samples in different RH levels will inevitably generate greater sample differences. This can be solved by enlarging the sample group and by evenly distributing sample densities in each group. The second uncertainty is the influence of intermediate $\mathrm{RH}$ levels and historical paths. Obviously putting different samples into various RH levels simultaneously will skip many intermediate RHs and thus requires large RH steps (from RH $0 \%$ to $95 \%$, for example). Peuhkuri showed that the influence of RH step size on the EMC and sorption curves was negligible for five measured materials [36]. However, more investigations are indispensable, because not much support is currently available.

Furthermore, in the practice of putting the same group of samples in rising/falling RH sequences for equilibrium, the more $\mathrm{RH}$ levels there are, the more time it takes. Thus it is common practice to determine EMCs at 4-9 different RHs [35, 49, 50, 53-55]. For theoretical analysis and engineering practice, it is desirable to have continuous functions to describe the sorption curves, rather than some discrete points. As a result, different models have been proposed for curve fitting. By 1978 there had 
Postprint: Feng C, Janssen H, Wu C, Feng Y, Meng Q. 2013. Validating various measures to accelerate the static gravimetric sorption isotherm determination, Building and Environment, 69:64-71.

doi: 10.1016/j.buildenv.2013.08.005

already been at least 23 different models [56] and by now the number may have reached 50 or even more. Of all these models, some are physically based and thus have a theoretical foundation - such as the BET model [57] - while other models are semi- or completely empirical - such as the Peleg model [58]. If the physical foundation is not the focal issue, it suffices to find a mathematical function that fits the experimental data well. The function preferably contains only a limited number of parameters, and if possible, yields reliable results with a restricted number of test points [58, 59].

Last but not least, in both the ISO 12571 standard [32] and the ASTM C1498 standard [33], 23 ${ }^{\circ} \mathrm{C}$ is prescribed as the single temperature for sorption tests. To repeat sorption tests at many different temperatures, an overwhelming amount of time is needed. As a result, many scholars just performed tests at room temperature $\left(20-25^{\circ} \mathrm{C}\right)$ without looking into the temperature dependence of sorption isotherms. Some test results are available for certain building materials, as well as for some other porous media (such as food and soil) [35, 44-46, 51, 53, 55, 60-63]. Generally speaking, temperature tends to have greater influence on organic materials and on the desorption process. For a more profound understanding of this issue, more experimental results are required. We studied the influence of temperature on the sorption isotherms by conducting both adsorption and desorption tests at $15^{\circ} \mathrm{C}, 25^{\circ} \mathrm{C}$ and $35^{\circ} \mathrm{C}$, but this analysis will not be reported in this paper.

\subsection{Objectives}

This paper aims at investigating several measures to speed up the static gravimetric test for determining the sorption isotherms of autoclaved aerated concrete at $25^{\circ} \mathrm{C}$. Specifically, these measures include:

a) Using oven drying at elevated temperature instead of desiccant drying at room temperature;

b) Using small samples instead of large samples;

c) Using different samples at different RH levels simultaneously instead of exposing the same samples to sequential RH levels;

d) Using a mathematical model to fit sorption isotherms with few experimental points.

\section{Material and methods}

\subsection{Material description}

Autoclaved aerated concrete (AAC) is a popular building material in many countries, and is therefore chosen as the target material in this paper. Test samples are cut from AAC blocks provided by Dongguan Chuangjian New Building Materials Co., Ltd. The blocks are of Chinese B07 density grade (the dry density is no more than $700 \mathrm{~kg} / \mathrm{m}^{3}$ ) and A5.0 strength grade (the compressive strength of cubes is no less than 5.0 MPa). 80 samples in two sizes are employed. These samples are contained in small glass weighing cups (inner diameter: $6.5 \mathrm{~cm}$, depth: $2.5 \mathrm{~cm}$ ) during all drying and sorption processes. Table 1 summarizes some important basic properties of samples.

\subsection{Sample groups}

The bulk density of each sample is calculated with the dry mass obtained from oven drying at $70^{\circ} \mathrm{C}$ and the dimensions measured at room temperature (bulk density 1 in Table 1 ). In addition, 10 large and 10 small samples are selected for the vacuum saturation test at room temperature and their bulk densities are also obtained this way (bulk density 2 in Table 1). The different bulk density 1 for large and small samples should be mainly attributed to the experimental errors, especially in the measurement of dimensions. The different bulk density 2 for large and small samples can be 
Postprint: Feng C, Janssen H, Wu C, Feng Y, Meng Q. 2013. Validating various measures to accelerate the static gravimetric sorption isotherm determination, Building and Environment, 69:64-71.

doi: 10.1016/j.buildenv.2013.08.005

explained by the slightly different open porosities, stemming from the different original positions in the AAC blocks from which large and small samples are cut.

Since not all samples have undergone the vacuum saturation test, we group samples according to the bulk density 1. One large sample and two small ones with abnormal bulk densities are discarded, and so are the redundant samples. Finally 32 large samples and 32 small ones are retained. Large samples are grouped into 8 groups of 4 samples each. The grouping criterion is that the density distribution in each group should be similar. This is confirmed by Duncan's multiple range tests [64]. The small samples are similarly distributed into 8 groups.

Table 1 Basic properties of AAC samples ${ }^{\text {a }}$

\begin{tabular}{|c|c|c|}
\hline Size & Large & Small \\
\hline Dimensions $\left(\mathrm{mm}^{3}\right)$ & $40.52(0.62) \times 40.52(0.62) \times 19.27(0.36)$ & $28.80(0.26) \times 28.79(0.31) \times 9.26(0.09)$ \\
\hline Dry mass $\left(\mathrm{g}, 70^{\circ} \mathrm{C}\right.$ oven dried $)$ & $18.9153(0.9153)$ & $4.4272(0.1309)$ \\
\hline Bulk density $1^{\mathrm{b}}\left(\mathrm{kg} / \mathrm{m}^{3}\right)$ & $597.3(13.1)$ & $576.8(14.9)$ \\
\hline Bulk density $2^{\mathrm{c}}\left(\mathrm{kg} / \mathrm{m}^{3}\right)$ & $643.1(9.8)$ & $662.9(6.8)$ \\
\hline $\begin{array}{l}\text { Apparent matrix density }{ }^{\mathrm{c}} \\
\left(\mathrm{kg} / \mathrm{m}^{3} \text {, with closed pores }\right)\end{array}$ & 2621.1(5.2) & 2618.7(4.0) \\
\hline Open porosity ${ }^{\mathrm{c}}(\%)$ & $75.5(0.4)$ & $74.7(0.3)$ \\
\hline
\end{tabular}

a. Standard deviations are indicated in parentheses;

b. Determined from ordinary dimension and dry mass measurements, for all samples;

c. Determined from vacuum saturation tests, for 10 large and 10 small samples.

\subsection{Drying methods}

Three drying methods are adopted in our study: desiccant drying at room temperature, and oven drying at $70^{\circ} \mathrm{C}$ and $105^{\circ} \mathrm{C}$. For the desiccant drying method, powdered $\mathrm{CaCl}_{2}$ has been heated to $200^{\circ} \mathrm{C}$ for over $24 \mathrm{~h}$ and then cooled in sealed desiccators for use. Two groups of large and two groups of small samples are kept in the desiccator with desiccant at room temperature (around $20^{\circ} \mathrm{C}$ ) for one month, and then weighed at intervals of 7-10 days. For the oven drying at $105^{\circ} \mathrm{C}$, the same two groups of large samples and two groups of small samples are used. For the oven drying at $70^{\circ} \mathrm{C}$, all samples are used. These samples are kept in an oven at fixed temperatures for five days and then weighed at intervals of 2-3 days.

In the actual weighing process for the oven dried samples, all weighing cups (with samples inside) are taken out from the oven and tight-fitting lids are put on quickly. The weighing cups are then placed in desiccators with desiccant $\left(\mathrm{CaCl}_{2}\right)$, until samples have naturally cooled to room temperature. Subsequently, the weighing cups with samples are weighed by an analytical balance reading $0.0001 \mathrm{~g}$. After that samples are returned to oven for further drying and weighing. For the desiccant drying method, no cooling process is involved and all other processes are the same. Equilibrium is assumed to have been reached when three successive weighing results at intervals of at least $48 \mathrm{~h}$ do no longer show monotonous mass evolutions and when their relative deviations are below $0.1 \%$.

\subsection{Adsorption and desorption tests}

The static gravimetric method is used to determine the EMC of samples. Eight desiccators with different saturated salt solutions are placed in a climate chamber where temperature is controlled at 
Postprint: Feng C, Janssen H, Wu C, Feng Y, Meng Q. 2013. Validating various measures to accelerate the static gravimetric sorption isotherm determination, Building and Environment, 69:64-71.

doi: 10.1016/j.buildenv.2013.08.005

$25 \pm 0.3^{\circ} \mathrm{C}$. Table 2 shows the solutions used and the related equilibrium RHs in the desiccators.

After oven drying at $70^{\circ} \mathrm{C}$, samples are put into desiccators for adsorption. Each desiccator holds one group of large samples and one group of small ones. Samples are weighed at intervals of at least two days. When three successive readings are within $0.1 \%$ fluctuation, equilibrium is assumed to have been reached. Then samples at higher RHs are placed into lower RHs for the desorption tests.

Table 2 Saturated salt solutions used and the RHs of ambient air at $25^{\circ} \mathrm{C}$ [32]

\begin{tabular}{cccc}
\hline Solution & $\mathrm{RH}(\%)$ & Solution & $\mathrm{RH} \mathrm{( \% )}$ \\
\hline $\mathrm{LiCl}$ & 11.3 & $\mathrm{NaCl}$ & 75.3 \\
$\mathrm{MgCl}_{2}$ & 32.8 & $\mathrm{KCl}$ & 84.3 \\
$\mathrm{~K}_{2} \mathrm{CO}_{3}$ & 43.2 & $\mathrm{KNO}_{3}$ & 93.6 \\
$\mathrm{NaBr}$ & 57.6 & $\mathrm{~K}_{2} \mathrm{SO}_{4}$ & 97.3 \\
\hline
\end{tabular}

It should be noted that in our tests the starting RH levels of the desorption tests are different, so the test points represent both the main and different primary desorption curves. Since no complete main or primary desorption curves have been obtained, the fitting of the desorption isotherm in this paper has no physical meaning. However, even this virtual fitting provides useful information about the adaptability of different fitting models.

Moreover, for both the drying and the sorption tests, we perform the weighing process in standard room air with an $\mathrm{RH}$ of 50-60\%, rather than opening the oven and desiccators in an environment in equilibrium with the relative humidity of the oven/desiccator. Consequently, there is a chance of moisture transfer between samples and ambient air in the weighing process. This influence is negligible, as discussed in the appendix.

\subsection{Fitting models}

Six widely adopted models for the fitting of sorption isotherms are summarized in Table 3 . A new mathematical model proposed by us is also introduced with minor simplification from its previous expression [65]. It should be noted that although the BET model [57] is perhaps the most famous one, it is well known that it focuses on the adsorption rather than the desorption process, and is only valid up to $50 \%$ RH $[52,56-58]$. Consequently, the BET model is not included here.

Table 3 Seven models for fitting sorption isotherms

\begin{tabular}{ccc}
\hline Model name & Formula $^{\mathrm{a}}$ & Number of parameters \\
\hline Oswin [59] & $u=k_{1}[\varphi /(1-\varphi)]^{k_{2}}$ & 2 \\
Henderson [66] & $\left.u=\left\{[\ln (1-\varphi)] / k_{1}\right]\right\}^{k_{2}}$ & 2 \\
Caurie [67] & $u=\exp \left(k_{1}+k_{2} \varphi\right)$ & 2 \\
GAB [68] & $u=k_{1} k_{2} k_{3} \varphi /\left[\left(1-k_{1} \varphi\right)\left(1-k_{2} \varphi+k_{2} k_{3} \varphi\right)\right]$ & 3 \\
Hansen [69] & $u=k_{1}\left[1-(\ln \varphi) / k_{2}\right]^{-1 / k_{3}}$ & 3 \\
Peleg [58] & $u=k_{1} \varphi^{k_{2}}+k_{3} \varphi^{k 4}$ & 4 \\
Our new model [65] & $u=\ln \left[(100 \varphi+1)^{k_{1}} /(1-\varphi)^{k_{2}}\right]+k_{3} \exp (100 \varphi)$ & 3 \\
\hline
\end{tabular}

a. $\mathrm{u}$ is the $\mathrm{EMC}(\mathrm{kg} / \mathrm{kg}), \varphi$ the $\mathrm{RH}(0-1), \mathrm{k}_{1} 、 \mathrm{k}_{2} \ldots$ the fitting parameters.

\section{Results and discussion}

The OriginPro 8.6 software is used for the statistical analysis and curve fitting. The significance 
Postprint: Feng C, Janssen H, Wu C, Feng Y, Meng Q. 2013. Validating various measures to accelerate the static gravimetric sorption isotherm determination, Building and Environment, 69:64-71.

doi: 10.1016/j.buildenv.2013.08.005

level is set as $\alpha=0.05$.

\subsection{Drying methods}

\subsubsection{Weighing precision}

The dry mass of each sample is taken as the mean value of three successive weighing results at intervals of at least 48 hours showing non-monotonous relative deviations below $0.1 \%$. The standard deviation of these three weighing results reflects the fluctuations of one sample's dry mass readings. By averaging the relative standard deviation of all samples, we can obtain an indicator of both the weighing errors involved and the differences between samples. As the differences between samples within groups can be assumed reasonably similar from group to group, the calculated results should mainly reflect the stability of different drying methods. The detailed figures are $0.034 \%, 0.062 \%$ and $0.089 \%$ for desiccant drying at room temperature, oven drying at $70^{\circ} \mathrm{C}$, and oven drying at $105^{\circ} \mathrm{C}$ respectively, showing that the desiccant drying method provides the most stable dry mass readings while oven drying at $105^{\circ} \mathrm{C}$ comes last. This can be explained by the time needed for the cooling process, which leads to experimental errors.

In short, desiccant drying is the best in terms of the weighing precision. But basically the weighing precisions are satisfactory for all three drying methods.

\subsubsection{Dry mass comparison}

The direct comparison of all samples' average dry mass obtained from three different drying methods is meaningless because samples of roughly the same size do not necessarily have the same dry mass. To solve the problem we set the dry mass from one drying method as the reference and convert the dry mass from the other two methods accordingly. Since desiccant drying at room temperature is the most stable in terms of weighing precision, we set the dry mass obtained from this method as 100 units. Table 4 summarizes the average values of the converted dry mass and the standard deviations.

Table 4 Comparison of the dry mass from different drying methods

\begin{tabular}{lcccc}
\hline \multicolumn{2}{c}{ Drying method } & $\begin{array}{c}\text { Desiccant drying at } \\
\text { room temperature }\end{array}$ & Oven drying at $70^{\circ} \mathrm{C}$ & Oven drying at $105^{\circ} \mathrm{C}$ \\
\hline \multirow{2}{*}{$\begin{array}{c}\text { Mean relative } \\
\text { dry mass }\end{array}$} & Large samples & $100.00(0)$ & $100.13(0.08)$ & $98.98(0.04)$ \\
\cline { 2 - 5 } & Small samples & $100.00(0)$ & $100.16(0.06)$ & $98.94(0.03)$ \\
\hline $\begin{array}{l}\text { a. } \\
\text { b. Standard deviations are indicated in parenthesis; }\end{array}$ & \\
b. The mass from desiccant drying at room temperature is set as 100 units.
\end{tabular}

According to Table 4, the dry mass from oven drying at $70^{\circ} \mathrm{C}$ is quite close to that from desiccant drying at room temperature. The mean difference is merely $0.14 \%$, and can most probably be attributed to the small differences in the final $\mathrm{RH}$ levels: the $\mathrm{RH}$ for the desiccant drying is around $1-2 \%$, while it is about $4 \%$ for the oven drying (the oven takes in air from the lab environment, where the $\mathrm{RH}$ is roughly $50-60 \%$ ). To sum, oven drying at $70^{\circ} \mathrm{C}$ and desiccant drying at room temperature can give almost the same dry mass, except for some minor experimental errors.

Table 4 furthermore shows that the dry mass obtained from oven drying at $105^{\circ} \mathrm{C}$ is over $1 \%$ lower than that obtained from desiccant drying at room temperature. This difference is quite significant, because it can result in more than $1 \%$ EMC difference $(\mathrm{kg} / \mathrm{kg})$. For a material with low EMC (such as AAC), such a deviation is rather big. The main reason for this difference is that water in materials exists in various physical or chemical states. Besides the physically bound water, oven drying at $105^{\circ} \mathrm{C}$ also evaporates some of the chemically bound water $[39,54,70]$. 
It is also clearly reflected in Table 4 that for large and small samples the converted dry mass from the same drying method is almost identical, and the differences between large and small samples are much smaller than the differences among different drying methods. This indicates that the differences in dry mass in Table 4 originate from drying methods, rather than from sample's sizes.

\subsubsection{Conclusions on drying methods}

The test efficiency, material protection and weighing precision can be used as the criteria for choosing the best drying method:

a. In our experiment desiccant drying at room temperature takes far more time (around two months) than the oven drying method (less than a week). Consequently, in terms of the test efficiency, the oven drying method is obviously preferable.

b. Oven drying at $105^{\circ} \mathrm{C}$ will evaporate some of the chemically bound water, as reflected by the differences in the dry mass from oven drying at $70^{\circ} \mathrm{C}$ and $105^{\circ} \mathrm{C}$. A high temperature may also lead to pore structure changes and tiny cracks to cement-based materials [37, 40, 71]. To avoid these risks, oven drying at $70^{\circ} \mathrm{C}$ is superior to oven drying at $105^{\circ} \mathrm{C}$.

c. All three drying methods have satisfactory weighing precision. If a preference needs to be stated, desiccant drying at room temperature comes first and oven drying at $105^{\circ} \mathrm{C}$ is the last choice.

In short, oven drying at $70^{\circ} \mathrm{C}$ can accelerate the drying process impressively while achieving almost the same dry mass as desiccant drying at room temperature, without sacrificing experimental precision or introducing severe deformation to the material. Thus we recommend oven drying at $70^{\circ} \mathrm{C}$ as the best drying method for AAC, as well as for other materials which do not experience chemical reactions or irreversible structural changes at $70^{\circ} \mathrm{C}$. All data reported in the following parts of this paper are based on the dry mass obtained from oven drying at $70^{\circ} \mathrm{C}$.

\subsection{Sample sizes}

\subsubsection{EMC comparison}

For each RH level, the EMCs of four large samples and four small samples have been obtained. Fig. 1 illustrates these EMCs for both adsorption and desorption processes. It is worth mentioning that the EMCs of small samples at RH 84.3\% during desorption are flawed by experimental mistakes, and the corresponding bar is thus not shown.

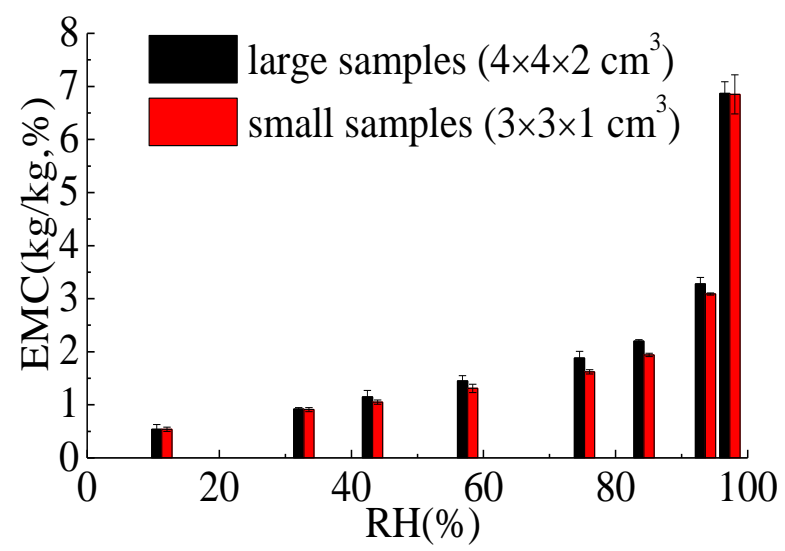

a. Adsorption process

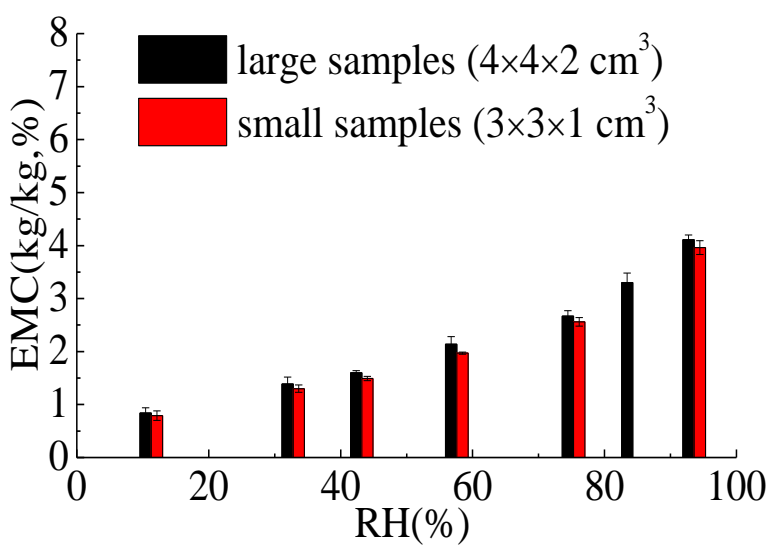

b. Desorption process

Fig. 1 EMCs of large and small AAC samples at $25^{\circ} \mathrm{C}$ 
Postprint: Feng C, Janssen H, Wu C, Feng Y, Meng Q. 2013. Validating various measures to accelerate the static gravimetric sorption isotherm determination, Building and Environment, 69:64-71.

doi: 10.1016/j.buildenv.2013.08.005

Fig.1 shows that the EMCs of large samples slightly exceed the EMCs of small ones throughout the studied RH range. However, the differences are small when compared with the standard deviations of duplicate samples in the same group. The independent $T$-tests furthermore show that only in one third of all cases that the differences are statistically different. The details for the independent $T$-test can be found in Ref. [64]. In conclusion, if the calculated significance is greater than the selected significance level, then the mean values of two groups of numbers are statistically the same; otherwise they are statistically different.

In addition, as is shown in Table 1, large and small samples have different open porosities, which determine the EMCs. Thus the EMC differences should be most probably attributed to these porosity differences, rather than reflecting the actually differences between large and small samples.

Last but not least, from the results of the EC HAMSTAD project [23], in which many round robin tests were performed to determine the hygrothermal properties of three building materials (the autoclaved aerated concrete, the calcium silicate board and the ceramic brick), we can easily tell that the EMCs of the same material at the same RH level obtained by different laboratories are noticeably different. The discrepancies among laboratories are much larger than the EMC differences between large and small samples in our case.

To sum, large and small samples can provide almost the same EMCs throughout the whole RH range, except for some minor differences.

\subsubsection{Test efficiency}

It is well known that by using small samples the test efficiency of sorption tests can be improved dramatically $[44,45]$. In our adsorption tests, small samples save up to 50 days to reach equilibrium (different improvements for different RH paths), while the overall test period for large samples is nearly 3 months. Obviously the improvement is impressive.

Moreover, the advantage of small samples could be further enhanced. At the moment, the combination of the still air in the desiccator and the use of weighing cups yields a slow vapor exchange with the samples, making the surface vapor resistance a dominant factor for the diffusion into or out of the samples. Installation of small fans in the desiccators can substantially reduce such transfer resistances, and in that case smaller, thinner samples will become even more advantageous. In our current follow-up tests with such set-up, it takes less than one month for samples to reach equilibrium, even when the sorption path is from the oven dried state to $97.3 \% \mathrm{RH}$.

\subsubsection{Conclusions on sample sizes}

Firstly, small samples improve test efficiency a lot. Secondly, small samples provide almost the same results as large samples without sacrificing experimental precision. Consequently, we advocate small samples. However, it should be kept in mind that the samples should not be too small in comparison to the accuracy of the balance - the accuracy of the balance should be at least 0.01-0.1 percent of a sample's mass, as required by ISO 12571 [32] and ASTM C1498 [33].

It should be noted that, due to the original experimental arrangement, we carry out most tests with large samples. To keep things consistent, all data reported in the following parts of this paper are based on the EMCs of large samples.

\subsection{RH levels}

As mentioned in Section 1.2, it is common practice to expose different samples to different $\mathrm{RH}$ levels simultaneously for efficiency. To verify whether intermediate RH levels have an influence on 
Postprint: Feng C, Janssen H, Wu C, Feng Y, Meng Q. 2013. Validating various measures to accelerate the static gravimetric sorption isotherm determination, Building and Environment, 69:64-71.

doi: 10.1016/j.buildenv.2013.08.005

the EMC, we compare the EMCs of samples with different RH paths throughout the whole RH range in Table 5. It should be noted that due to the experimental arrangement, not all tests in Table 5 are conducted at the same temperature. But this should have no influence on the conclusion. For reliable statistical conclusions, independent $T$-tests are again performed and summarized in Table 5.

Table 5 EMC comparison for different RH paths

\begin{tabular}{|c|c|c|c|c|}
\hline \multirow[b]{2}{*}{$\begin{array}{l}\text { Temperature } \\
\left({ }^{\circ} \mathrm{C}\right)\end{array}$} & \multirow[b]{2}{*}{ RH path } & \multicolumn{2}{|c|}{ EMC (kg/kg, \%) } & \multirow[b]{2}{*}{ Significance } \\
\hline & & Mean & $\begin{array}{l}\text { Standard } \\
\text { deviation }\end{array}$ & \\
\hline 15 & Oven dried-11.3-33.3 & 0.93 & 0.08 & 0.068 \\
\hline 15 & Oven dried-33.3 & 0.82 & 0.06 & 0.068 \\
\hline 15 & $\begin{array}{l}\text { Oven dried-33.3-43.2 } \\
\text { Oven dried- } 43.2\end{array}$ & $\begin{array}{l}0.98 \\
106\end{array}$ & 0.06 & 0.393 \\
\hline 25 & $\begin{array}{l}\text { Oven dried-43.2-75.3 } \\
\text { Oven dried-75.3 }\end{array}$ & $\begin{array}{l}1.75 \\
1.88\end{array}$ & $\begin{array}{l}0.12 \\
0.13\end{array}$ & 0.183 \\
\hline 25 & $\begin{array}{l}\text { Oven dried-75.3-93.6 } \\
\text { Oven dried-93.6 }\end{array}$ & $\begin{array}{l}3.12 \\
3.28\end{array}$ & $\begin{array}{l}0.12 \\
0.12\end{array}$ & 0.121 \\
\hline
\end{tabular}

It is clearly reflected in Table 5 that the EMCs in the adsorption process remain almost the same if the final $\mathrm{RH}$ level is the same. In most cases the differences are less than $0.1 \%(\mathrm{~kg} / \mathrm{kg})$ while the maximum difference is merely $0.16 \%(\mathrm{~kg} / \mathrm{kg})$. These limited differences are in the same order of the EMC scatters within groups and are negligible in most situations, as proved by the significance of independent $T$-tests. Thus we observe that the EMC of samples in the adsorption process is not affected by the samples' previous sorption histories, as long as a one-way adsorption process is imposed. It is therefore reasonable to expose many samples to different RH levels simultaneously to speed up the overall adsorption tests.

\subsection{Fitting models}

It is widely accepted that, to compare the fitting results of different models, the coefficient of determination $\left(\mathrm{R}^{2}\right)$ is insufficient as the sole judging criterion [44-49, 52]. In this paper, the residual sum of square (RSS) and the distribution of residuals are also taken into account.

The RSS is defined as:

$$
R S S=\sum_{1}^{n}\left(x-x_{f i t}\right)^{2}
$$

where $\mathrm{x}$ and $\mathrm{x}_{\mathrm{fit}}$ are the measured values from experiments and the predicted values from the fitting curve respectively. Obviously, the smaller the RSS is, the better the fitting curve is.

In addition, Fig. 2 illustrates the fitting results of the GAB and Peleg models in the adsorption process, while Fig. 3 illustrates the residual plots accordingly. It can be easily understood that the random distribution is better, because patterned residual distribution indicates that the fitting tends to wrongfully represent the data. The fitting results are summarized in Table 6 .

It is clearly reflected in Table 6 that for the adsorption process, the Henderson and Caurie models result in relatively small $\mathrm{R}^{2}$ and big RSS values, and should therefore be excluded. Moreover, although the Oswin, GAB and Hansen models give acceptable $\mathrm{R}^{2}$ and RSS values, their distributions of residuals are all patterned, indicating the fitting results of these three models are not very good either. As a result, the Peleg model and our new model are the best for the adsorption process.

When it comes to the desorption process, all seven models give good fitting results and no 
Postprint: Feng C, Janssen H, Wu C, Feng Y, Meng Q. 2013. Validating various measures to accelerate the static gravimetric sorption isotherm determination, Building and Environment, 69:64-71.

doi: 10.1016/j.buildenv.2013.08.005

obviously patterned distribution of residuals can be observed. Considering the fitting results of adsorption process at the same time, the Peleg model and our new model remain as the last choices. Our new model has one fewer parameter than the Peleg model and therefore has narrower chance for the problem of over-parameterization (non-unique fitting). Moreover, it provides slightly better fitting results than the Peleg model. Consequently, we conclude that our new model is preferable.

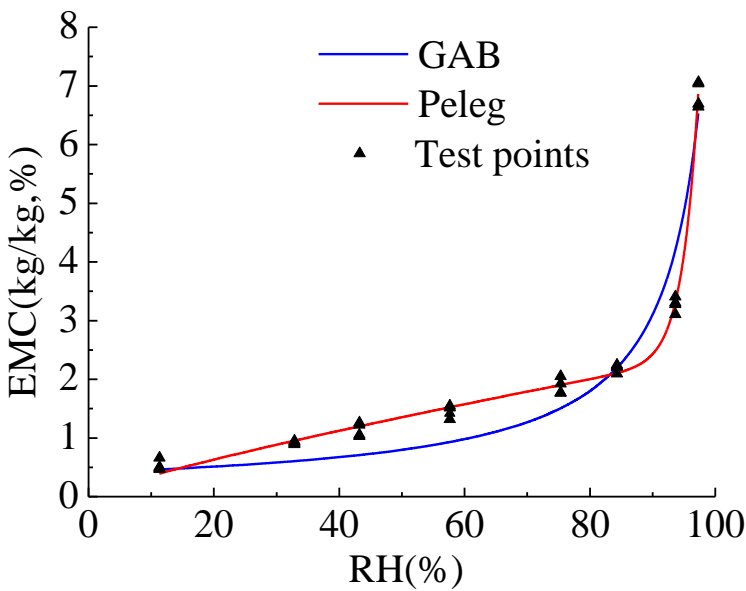

Fig. 2 Adsorption fittings with GAB and Peleg models

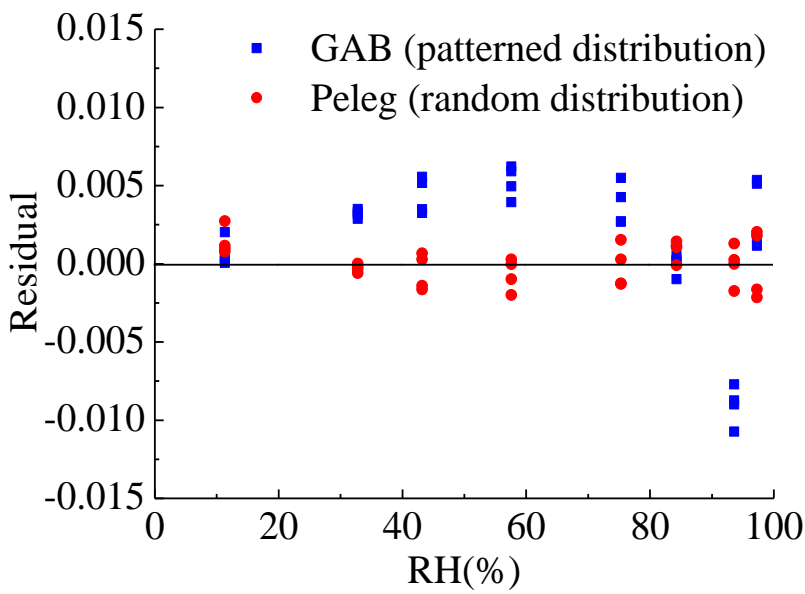

Fig. 3 Residual plots of the fitting with GAB and Peleg models (adsorption)

Table 6 Fitting results of different models

\begin{tabular}{ccccccccc}
\hline \multirow{2}{*}{ Process } & Model & $\mathrm{k}_{1}$ & $\mathrm{k}_{2}$ & $\mathrm{k}_{3}$ & $\mathrm{k}_{4}$ & $\mathrm{R}^{2}$ & \multirow{2}{*}{$\mathrm{RSS}$} & Residual plot \\
\hline \multirow{5}{*}{ Adsorption } & Oswin & 0.00988 & 0.525 & & & 0.961 & $4.54 \times 10^{-4}$ & Patterned \\
& Henderson & -31.84 & 1.28 & & & 0.898 & 0.0012 & Patterned \\
& Caurie & -7.70 & 4.94 & & & 0.798 & 0.0024 & Patterned \\
& GAB & 0.00414 & 0.963 & $5.55 \times 10^{45}$ & & 0.940 & $6.94 \times 10^{-4}$ & Patterned \\
& Hansen & 6.461 & $9.18 \times 10^{-6}$ & 1.743 & & 0.971 & $3.32 \times 10^{-4}$ & Patterned \\
& Peleg & 0.130 & 38.751 & 0.024 & 0.831 & 0.996 & $5.07 \times 10^{-5}$ & Random \\
& New model & 0.00165 & 0.0086 & $1.662 \times 10^{-44}$ & & 0.996 & $4.80 \times 10^{-5}$ & Random \\
\hline \multirow{5}{*}{ Desorption } & Oswin & 0.0184 & 0.312 & & & 0.977 & $7.21 \times 10^{-5}$ & Random \\
& Henderson & -840.83 & 0.560 & & & 0.985 & $4.71 \times 10^{-5}$ & Random \\
& Caurie & -4.94 & 1.84 & & & 0.982 & $5.66 \times 10^{-5}$ & Random \\
& GAB & 0.01046 & 0.801 & $-6.86 \times 10^{45}$ & & 0.972 & $8.94 \times 10^{-5}$ & Random \\
& Hansen & 0.04889 & 0.244 & 1.345 & & 0.988 & $3.92 \times 10^{-5}$ & Random \\
& Peleg & 0.024 & 5.003 & 0.025 & 0.513 & 0.988 & $3.84 \times 10^{-5}$ & Random \\
& New model & 0.0027 & 0.01117 & $-4.314 \times 10^{-44}$ & & 0.989 & $3.64 \times 10^{-5}$ & Random \\
\hline
\end{tabular}

\section{Conclusions}

This paper examines several widely adopted measurements for improving the efficiency of the static gravimetric test for determining the sorption isotherms. Autoclaved aerated concrete is chosen as the target material and the test temperature is $25^{\circ} \mathrm{C}$. Specifically, the following results are obtained:

a. Three different drying methods (desiccant drying at room temperature, as well as oven drying at $70^{\circ} \mathrm{C}$ and $105^{\circ} \mathrm{C}$ respectively) have been compared. Oven drying at $70^{\circ} \mathrm{C}$ can accelerate the drying process impressively while achieving almost the same dry mass as desiccant drying at room temperature, without sacrificing experimental reliability.

b. Large and small samples provide almost the same EMCs throughout the whole RH range, while 
Postprint: Feng C, Janssen H, Wu C, Feng Y, Meng Q. 2013. Validating various measures to accelerate the static gravimetric sorption isotherm determination, Building and Environment, 69:64-71.

doi: 10.1016/j.buildenv.2013.08.005

small samples take less time to reach equilibrium. The slight EMC differences are negligible in light of the porosity difference and experimental uncertainty.

c. The effect of intermediate RH levels on the EMC is negligible, as long as a one-way adsorption process is imposed. It is therefore acceptable to expose samples to different $\mathrm{RH}$ levels simultaneously to speed up the overall tests.

d. A new mathematical model is introduced to fit the sorption curves of AAC. It works better than the Oswin, Henderson, Caurie, GAB, Hansen and Peleg models.

\section{Acknowledgments}

This project is supported by the National Key Technology R\&D Program of China (Project No. 2011BAJ01B01). The first author (Chi Feng) is also financially supported by China Scholarship Council for his study at K.U. Leuven. The authors express sincere thanks to Professor Yufeng Zhang, as well as to master students $\mathrm{Xi} \mathrm{Yu}$ and Chao Jiang in South China University of Technology for their help in carrying out the experiments.

\section{References}

[1] Datta AK. Porous media approaches to studying simultaneous heat and mass transfer in food processes. I: Problem formulations. J Food Eng. 2007;80:80-95.

[2] Datta AK. Porous media approaches to studying simultaneous heat and mass transfer in food processes. II: Property data and representative results. J Food Eng. 2007;80:96-110.

[3] Poornesh KK, Cho C. Poroelastic PEM fuel cell catalyst layer and its implication in predicting the effect of mechanical load on flow and transport properties. Int J Hydrogen Energy. 2011;36:3623-34.

[4] Becker J, Wieser C, Fell S, Steiner K. A multi-scale approach to material modeling of fuel cell diffusion media. Int J Heat Mass Transf. 2011;54:1360-8.

[5] Missirlis D, Donnerhack S, Seite O, Albanakis C, Sideridis A, Yakinthos K, et al. Numerical development of a heat transfer and pressure drop porosity model for a heat exchanger for aero engine applications. Appl Therm Eng. 2010;30:1341-50.

[6] Tuli A, Hopmans JW, Rolston DE, Moldrup P. Comparison of air and water permeability between disturbed and undisturbed soils. Soil Sci Soc Am J. 2005;69:1361-71.

[7] Wang QJ, Shao M, Horton R. A simple method for estimating water diffusivity of unsaturated soils. Soil Sci Soc Am J. 2004;68:713-8.

[8] Chau KW. Investigation on effects of aggregate structure in water and wastewater treatment. Water Sci Technol. 2004;50:119-24.

[9] Stoltz G, Gourc J-P, Oxarango L. Liquid and gas permeabilities of unsaturated municipal solid waste under compression. J Contam Hydrol. 2010;118:27-42.

[10] Hribersek M, Zajdela B, Hribernik A, Zadravec M. Experimental and numerical investigations of sedimentation of porous wastewater sludge flocs. Water Res. 2011;45:1729-35.

[11] Geving S, Holme J. The Drying Potential and Risk for Mold Growth in Compact Wood Frame Roofs with Built-in Moisture. J Build Phys. 2010;33:249-69.

[12] Chen J, Ito K. Simplified prediction method for fungal growth risk in indoor environment coupled with heat and moisture transfer in building materials. J Environ Eng. 2010;75:603-11.

[13] Jaffer S, Hansson C. The influence of cracks on chloride-induced corrosion of steel in ordinary Portland cement and high performance concretes subjected to different loading conditions. Corros Sci. 2008;50:3343-55.

[14] Kwiatkowski J, Woloszyn M, Roux J-J. Influence of sorption isotherm hysteresis effect on indoor climate and 
Postprint: Feng C, Janssen H, Wu C, Feng Y, Meng Q. 2013. Validating various measures to accelerate the static gravimetric sorption isotherm determination, Building and Environment, 69:64-71.

doi: 10.1016/j.buildenv.2013.08.005

energy demand for heating. Appl Therm Eng. 2011;31:1050-7.

[15] Steeman M, Janssens A, Steeman HJ, Van Belleghem M, De Paepe M. On coupling 1D non-isothermal heat and mass transfer in porous materials with a multizone building energy simulation model. Build Environ. 2010;45:865-77.

[16] Woloszyn M, Kalamees T, Olivier Abadie M, Steeman M, Sasic Kalagasidis A. The effect of combining a relative-humidity-sensitive ventilation system with the moisture-buffering capacity of materials on indoor climate and energy efficiency of buildings. Build Environ. 2009;44:515-24.

[17] Simonson CJ, Salaonvaara M, Ojanen T. Heat and mass transfer between indoor air and a permeable and hygroscopic building envelope: part II "verification and numerical studies". J Therm Envel Build Sci. 2004;28:161-85.

[18] Simonson CJ, Salonvaara M, Ojanen T. Heat and mass transfer between indoor air and a permeable and hygroscopic building envelope: part I "Field measurements". J Therm Envel Build Sci. 2004;28:63-101.

[19] Zhang H, Yoshino H, Hasegawa K. Assessing the moisture buffering performance of hygroscopic material by using experimental method. Build Environ. 2012;48:27-34.

[20] Abuku M, Janssen H, Roels S. Impact of wind-driven rain on historic brick wall buildings in a moderately cold and humid climate: Numerical analyses of mould growth risk, indoor climate and energy consumption. Energy Build. 2009;41:101-10.

[21] dos Santos GH, Mendes N, Philippi PC. A building corner model for hygrothermal performance and mould growth risk analyses. Int J Heat Mass Transf. 2009;52:4862-72.

[22] Fang L, Clausen G, Fanger PO. Impact of temperature and humidity on the perception of indoor air quality. Indoor Air. 1998;8:80-90.

[23] Roels S, Carmeliet J, Hens H, Adan O, Brocken H, Czerny R, et al. HAMSTAD Work Package 1: Final Report Moisture Transfer Properties and Materials Characterisation. 2003.

[24] Kumaran MK. IEA Annex 24: Heat, Air and Moisture Transfer in Insulated Envelope Parts. Final Report, Volume 3 , Task 3: Material Properties.1996.

[25] Hens H. IEA Annex 14: Condensation and Energy, Volume 3: Catalogue of Material Properties.1991.

[26] Kumaran MK. Temperature dependence of water vapour permeability of glass fiber insulation from heat flow meter measurements. First ISHMT-ASME Heat and Mass Transfer Conference.1994. p. 645-51.

[27] Scheffler G, Grunewald J, Plagge R. Evaluation of functional approaches to describe the moisture diffusivity of building materials. J ASTM Int. 2007;4:1-16.

[28] Scheffler GA, Plagge R. A whole range hygric material model: Modelling liquid and vapour transport properties in porous media. Int J Heat Mass Transf. 2010;53:286-96.

[29] Van Belleghem M, Steeman H-J, Steeman M, Janssens A, De Paepe M. Sensitivity analysis of CFD coupled non-isothermal heat and moisture modelling. Build Environ. 2010;45:2485-96.

[30] Steeman HJ, Van Belleghem M, Janssens A, De Paepe M. Coupled simulation of heat and moisture transport in air and porous materials for the assessment of moisture related damage. Build Environ. 2009;44:2176-84.

[31] Kumaran MK. A Thermal and Moisture Transport Property Database for Common Building and Insulating Materials, Final Report from ASHRAE Research Project 1018-RP. 2002.

[32] ISO 12571: 2000(E) Hygrothermal performance of building materials and products - Determination of hygroscopic sorption properties. 2000.

[33] ASTM C1498 - 04a: Standard Test Method for Hygroscopic Sorption Isotherms of Building Materials. 2010.

[34] Janz M, Johannesson B. Measurement of the moisture storage capacity using sorption balance and pressure extractors. J Build Phys. 2001;24:316-34.

[35] Rode C, Hansen KK. Hysteresis and temperature dependency of moisture sorption - new measurements. 9th Nordic Symposium on Building Physics. 2011. p. 647-54. 
Postprint: Feng C, Janssen H, Wu C, Feng Y, Meng Q. 2013. Validating various measures to accelerate the static gravimetric sorption isotherm determination, Building and Environment, 69:64-71.

doi: 10.1016/j.buildenv.2013.08.005

[36] Peuhkuri R, Rode C, Hansen KK. Effect of method, step size and drying temperature on sorption isotherms. 7th Nordic Symposium on Building Physics. 2005. p. 31-8.

[37] Poyet S. Experimental investigation of the effect of temperature on the first desorption isotherm of concrete. Cem Concr Res. 2009;39:1052-9.

[38] Richards R, Burch D, Thomas W. Water vapor sorption measurements of common building materials. Trans-Am Soc Heat Refrig Air Cond Eng. 1992;98:475-85.

[39] Wilkes KE, Atchley JA, Childs PW. Effect of Drying Protocols on Measurement of Sorption Isotherms of Gypsum Building Materials. International Conference on Performance of Exterior Envelopes of Whole Buildings IX, Principles Track. 2004.

[40] Korpa A, Trettin R. The influence of different drying methods on cement paste microstructures as reflected by gas adsorption: Comparison between freeze-drying (F-drying), D-drying, P-drying and oven-drying methods. Cem Concr Res. 2006;36:634-49.

[41] Espinosa RM, Franke L. Influence of the age and drying process on pore structure and sorption isotherms of hardened cement paste. Cem Concr Res. 2006;36:1969-84.

[42] ISO 12570: 2000(E) Hygrothermal performance of building materials and products - Determination of moisture content by drying at elevated temperature. 2000.

[43] Koronthalyova O. Moisture storage capacity and microstructure of ceramic brick and autoclaved aerated concrete. Constr Build Mater. 2011;25:879-85.

[44] Swami SB, Das SK, Maiti B. Moisture sorption isotherms of black gram nuggets (bori) at varied temperatures. J Food Eng. 2005;67:477-82.

[45] Jamali A, Kouhila M, Ait Mohamed L, Jaouhari JT, Idlimam A, Abdenouri N. Sorption isotherms of Chenopodium ambrosioides leaves at three temperatures. J Food Eng. 2006;72:77-84.

[46] García-Pérez JV, Cárcel JA, Clemente G, Mulet A. Water sorption isotherms for lemon peel at different temperatures and isosteric heats. LWT - Food Sci Technol. 2008;41:18-25.

[47] Oyelade OJ, Tunde-Akintunde TY, Igbeka JC, Oke MO, Raji OY. Modelling moisture sorption isotherms for maize flour. J Stored Prod Res. 2008;44:179-85.

[48] Yan Z, Sousa-Gallagher MJ, Oliveira FAR. Sorption isotherms and moisture sorption hysteresis of intermediate moisture content banana. J Food Eng. 2008;86:342-8.

[49] Bejar AK, Mihoubi NB, Kechaou N. Moisture sorption isotherms - Experimental and mathematical investigations of orange (Citrus sinensis) peel and leaves. Food Chem. 2012;132:1728-35.

[50] Choudhury D, Sahu JK, Sharma GD. Moisture sorption isotherms, heat of sorption and properties of sorbed water of raw bamboo (Dendrocalamus longispathus) shoots. Ind Crops Prod. 2011;33:211-6.

[51] Labuza T, Kaanane A, Chen J. Effect of temperature on the moisture sorption isotherms and water activity shift of two dehydrated foods. J Food Sci. 1985;50:385-92.

[52] Arslan N, Toğrul H. The fitting of various models to water sorption isotherms of tea stored in a chamber under controlled temperature and humidity. J Stored Prod Res. 2006;42:112-35.

[53] de la Cruz GV , Torres JA, Martín-Polo MO. Temperature effect on the moisture sorption isotherms for methylcellulose and ethylcellulose films. J Food Eng. 2001;48:91-4.

[54] Roels S, Talukdar P, James C, Simonson CJ. Reliability of material data measurements for hygroscopic buffering. Int J Heat Mass Transf. 2010;53:5355-63.

[55] Poyet S, Charles S. Temperature dependence of the sorption isotherms of cement-based materials: Heat of sorption and Clausius-Clapeyron formula. Cem Concr Res. 2009;39:1060-7.

[56] Chirife J, Iglesias HA. Equations for fitting water sorption isotherms of foods: Part 1-a review. Int J Food Sci 
Postprint: Feng C, Janssen H, Wu C, Feng Y, Meng Q. 2013. Validating various measures to accelerate the static gravimetric sorption isotherm determination, Building and Environment, 69:64-71.

doi: 10.1016/j.buildenv.2013.08.005

Technol. 1978;13:159-74.

[57] Brunauer S, Emmett PH, Teller E. Adsorption of gases in multimolecular layers. J Am Chem Soc. 1938;60:309-19.

[58] Peleg M. Assessment of a semi-empirical four parameter general model for sigmoid moisture sorption isotherms. J Food Process Eng. 1993;16:21-37.

[59] Oswin C. The kinetics of package life. III. The isotherm. J Soc Chem Ind. 1946;65:419-21.

[60] Ajisegiri ES, Sopade PA. Moisture sorption isotherms of Nigerian millet at varying temperatures. J Food Eng. 1990;12:283-92.

[61] Palou E, Lopez-Malo A, Argaiz A. Effect of temperature on the moisture sorption isotherms of some cookies and corn snacks. J Food Eng. 1997;31:85-93.

[62] Wang N, Brennan JG. Moisture sorption isotherm characteristics of potatoes at four temperatures. J Food Eng. $1991 ; 14: 269-87$

[63] Bouyoucos G. Effect of temperature on the movement of water vapor and capillary moisture in soils. J Agric Resour. 1915;5:141-72.

[64] Montgomery DC. Design and analysis of experiments. 5th Edition. New York: John Wiley \& Sons Inc; 2008.

[65] Feng C, Meng Q, Janssen H, Feng Y. Effect of temperature on the sorption isotherm and vapor permeability. 2nd Central European Symposium on Building Physics. 2013.

[66] Henderson SM. A basic concept of equilibrium moisture. Agric Eng. 1952;33:29-32.

[67] Caurie M. A new model equation for predicting safe storage moisture levels for optimum stability of dehydrated foods. Int J Food Sci Technol. 1970;5:301-7.

[68] van den Berg C, Bruin S. Water activity and its estimation in food systems: theoretical aspects. In: L.B.Rockland, G.F.Stewart, editors. Water activity: Influences on food quality New York Academic Press; 1981. p. 2-61.

[69] Freiesleben Hansen P. Coupled moisture/heat transport in cross-sections of structures (in Danish). Beton og Konstruktionsinstituttet (BKI), Denmark. 1985.

[70] Al-Muhtaseb AH, McMinn WAM, Magee TRA. Moisture Sorption Isotherm Characteristics of Food Products: A Review. Food Bioprod Process. 2002;80:118-28.

[71] Gallé C. Effect of drying on cement-based materials pore structure as identified by mercury intrusion porosimetry: A comparative study between oven-, vacuum-, and freeze-drying. Cem Concr Res. 2001;31:1467-77. 
Postprint: Feng C, Janssen H, Wu C, Feng Y, Meng Q. 2013. Validating various measures to accelerate the static gravimetric sorption isotherm determination, Building and Environment, 69:64-71.

doi: 10.1016/j.buildenv.2013.08.005

\section{Appendix: Moisture transfer between samples and ambient air in the weighing process}

During the weighing process to determine the dry or moist mass, samples will be in contact with the ambient air for a short time. It is sometimes recommended to open the oven and desiccators only in an environment in equilibrium with the relative humidity of the oven/desiccator. As this is a major experimental complexity, the potential impact of this measure is analyzed first.

As can be calculated according to Table 1, the average surface area of small samples is $2.7 \times 10^{-3}$ $\mathrm{m}^{2}$. At $25^{\circ} \mathrm{C}$ and normal air pressure, the saturated vapor pressure is roughly $3166 \mathrm{~Pa}$. The surface vapor transfer coefficient can be assumed as $2 \times 10^{-8} \mathrm{~kg} /\left(\mathrm{m}^{2} \mathrm{sPa}\right)$, which is probably a worst-case-scenario value. By assuming the maximum vapor pressure difference (RH 0-100\%) between sample and ambient air, we obtain a moisture transfer rate of $1.7 \times 10^{-7} \mathrm{~kg} / \mathrm{s}$ for small samples.

With weighing cups, all samples in the desiccator or in the oven can be sealed within 20 seconds. Within this period a $3.4 \times 10^{-6} \mathrm{~kg}$ moisture transfer can happen, resulting in a minor $0.08 \%(\mathrm{~kg} / \mathrm{kg})$ EMC deviation. On the contrary, without weighing cups, the average exposing time is more than 2 minutes. The corresponding EMC deviation can reach $0.5 \%(\mathrm{~kg} / \mathrm{kg})$ or even more, which cannot be neglected easily. This is perhaps one of the reasons why both ISO 12571 and ASTM C1498 standards advocate the use of weighing cups. Large samples have a smaller specific surface area than small samples, and are therefore less sensitive to the influence.

All in all hence, it can be concluded that the contact with standard ambient air forms no threat to the precision of the dry and moist mass determinations, as long as weighing cups are used. 
Postprint: Feng C, Janssen H, Wu C, Feng Y, Meng Q. 2013. Validating various measures to accelerate the static gravimetric sorption isotherm determination, Building and Environment, 69:64-71.

doi: 10.1016/j.buildenv.2013.08.005

\section{Tables}

Table 1 Basic properties of AAC samples

Table 2 Saturated salt solutions used and the RHs of ambient air at $25^{\circ} \mathrm{C}$

Table 3 Seven models for fitting sorption isotherms

Table 4 Comparison of the dry mass from different drying methods

Table 5 EMC comparison for different RH paths

Table 6 Fitting results of different models

Table 1 Basic properties of AAC samples ${ }^{\text {a }}$

\begin{tabular}{ccc}
\hline Size & Large & Small \\
\hline Dimensions $\left(\mathrm{mm}^{3}\right)$ & $40.52(0.62) \times 40.52(0.62) \times 19.27(0.36)$ & $28.80(0.26) \times 28.79(0.31) \times 9.26(0.09)$ \\
Dry mass $\left(\mathrm{g}, 70^{\circ} \mathrm{C}\right.$ oven dried $)$ & $18.9153(0.9153)$ & $4.4272(0.1309)$ \\
Bulk density $1^{\mathrm{b}}\left(\mathrm{kg} / \mathrm{m}^{3}\right)$ & $597.3(13.1)$ & $576.8(14.9)$ \\
Bulk density $2^{\mathrm{c}}\left(\mathrm{kg} / \mathrm{m}^{3}\right)$ & $643.1(9.8)$ & $662.9(6.8)$ \\
Apparent matrix density & & \\
$\left(\mathrm{kg} / \mathrm{m}^{3}\right.$, with closed pores $)$ & $2621.1(5.2)$ & $2618.7(4.0)$ \\
Open porosity $^{\mathrm{c}}(\%)$ & $75.5(0.4)$ & $74.7(0.3)$ \\
\hline
\end{tabular}

a. Standard deviations are indicated in parentheses;

b. Determined from ordinary dimension and dry mass measurements, for all samples;

c. Determined from vacuum saturation tests, for 10 large and 10 small samples.

Table 2 Saturated salt solutions used and the RHs of ambient air at $25^{\circ} \mathrm{C}$ [32]

\begin{tabular}{cccc}
\hline Solution & $\mathrm{RH}(\%)$ & Solution & $\mathrm{RH}(\%)$ \\
\hline $\mathrm{LiCl}$ & 11.3 & $\mathrm{NaCl}$ & 75.3 \\
$\mathrm{MgCl}_{2}$ & 32.8 & $\mathrm{KCl}$ & 84.3 \\
$\mathrm{~K}_{2} \mathrm{CO}_{3}$ & 43.2 & $\mathrm{KNO}_{3}$ & 93.6 \\
$\mathrm{NaBr}$ & 57.6 & $\mathrm{~K}_{2} \mathrm{SO}_{4}$ & 97.3 \\
\hline
\end{tabular}

Table 3 Seven models for fitting sorption isotherms

\begin{tabular}{ccc}
\hline Model name & Formula $^{\mathrm{a}}$ & Number of parameters \\
\hline Oswin [59] & $u=k_{1}[\varphi /(1-\varphi)]^{k_{2}}$ & 2 \\
Henderson [66] & $\left.u=\left\{[\ln (1-\varphi)] / k_{1}\right]\right\}^{k_{2}}$ & 2 \\
Caurie [67] & $u=\exp \left(k_{1}+k_{2} \varphi\right)$ & 2 \\
GAB [68] & $u=k_{1} k_{2} k_{3} \varphi /\left[\left(1-k_{1} \varphi\right)\left(1-k_{2} \varphi+k_{2} k_{3} \varphi\right)\right]$ & 3 \\
Hansen [69] & $u=k_{1}\left[1-(\ln \varphi) / k_{2}\right]^{-1 / k_{3}}$ & 3 \\
Peleg [58] & $u=k_{1} \varphi^{k_{2}}+k_{3} \varphi^{k 4}$ & 4 \\
Our new model [65] & $u=\ln \left[(100 \varphi+1)^{k_{1}} /(1-\varphi)^{k_{2}}\right]+k_{3} \exp (100 \varphi)$ & 3 \\
\hline
\end{tabular}

a. $\mathrm{u}$ is the $\mathrm{EMC}(\mathrm{kg} / \mathrm{kg}), \varphi$ the $\mathrm{RH}(0-1), \mathrm{k}_{1} 、 \mathrm{k}_{2} \ldots$ the fitting parameters. 
Postprint: Feng C, Janssen H, Wu C, Feng Y, Meng Q. 2013. Validating various measures to accelerate the static gravimetric sorption isotherm determination, Building and Environment, 69:64-71.

doi: 10.1016/j.buildenv.2013.08.005

Table 4 Comparison of the dry mass from different drying methods

\begin{tabular}{ccccc}
\hline \multicolumn{2}{c}{ Drying method } & $\begin{array}{c}\text { Desiccant drying at } \\
\text { room temperature }\end{array}$ & Oven drying at $70^{\circ} \mathrm{C}$ & Oven drying at $105^{\circ} \mathrm{C}$ \\
\hline $\begin{array}{c}\text { Mean relative } \\
\text { dry mass }\end{array}$ & Large samples & $100.00(0)$ & $100.13(0.08)$ & $98.98(0.04)$ \\
\cline { 2 - 5 } & Small samples & $100.00(0)$ & $100.16(0.06)$ & $98.94(0.03)$ \\
\hline
\end{tabular}

a. Standard deviations are indicated in parenthesis;

b. The mass from desiccant drying at room temperature is set as 100 units.

Table 5 EMC comparison for different RH paths

\begin{tabular}{clccc}
\hline \multirow{2}{*}{$\begin{array}{c}\text { Temperature } \\
\left({ }^{\circ} \mathrm{C}\right)\end{array}$} & \multicolumn{1}{c}{ RH path } & EMC (kg/kg, \%) & \\
\cline { 3 - 4 } & & Mean & $\begin{array}{c}\text { Standard } \\
\text { deviation }\end{array}$ & \\
\hline \multirow{2}{*}{15} & Oven dried-11.3-33.3 & 0.93 & 0.08 & \multirow{2}{*}{0.068} \\
& Oven dried-33.3 & 0.82 & 0.06 & \\
\hline \multirow{2}{*}{15} & Oven dried-33.3-43.2 & 0.98 & 0.06 & \multirow{2}{*}{0.393} \\
& Oven dried-43.2 & 1.06 & 0.16 & \multirow{2}{*}{2.183} \\
\hline \multirow{2}{*}{25} & Oven dried-43.2-75.3 & 1.75 & 0.12 & 0.13 \\
& Oven dried-75.3 & 1.88 & 0.13 & \multirow{2}{*}{25} \\
& Oven dried-75.3-93.6 & 3.12 & 0.12 & 0.121 \\
\hline
\end{tabular}

Table 6 Fitting results of different models

\begin{tabular}{ccccccccc}
\hline Process & Model & $\mathrm{k}_{1}$ & $\mathrm{k}_{2}$ & $\mathrm{k}_{3}$ & $\mathrm{k}_{4}$ & $\mathrm{R}^{2}$ & $\mathrm{RSS}$ & Residual plot \\
\hline \multirow{5}{*}{ Adsorption } & Oswin & 0.00988 & 0.525 & & & 0.961 & $4.54 \times 10^{-4}$ & Patterned \\
& Henderson & -31.84 & 1.28 & & & 0.898 & 0.0012 & Patterned \\
& Caurie & -7.70 & 4.94 & & & 0.798 & 0.0024 & Patterned \\
& GAB & 0.00414 & 0.963 & $5.55 \times 10^{45}$ & & 0.940 & $6.94 \times 10^{-4}$ & Patterned \\
& Hansen & 6.461 & $9.18 \times 10^{-6}$ & 1.743 & & 0.971 & $3.32 \times 10^{-4}$ & Patterned \\
& Peleg & 0.130 & 38.751 & 0.024 & 0.831 & 0.996 & $5.07 \times 10^{-5}$ & Random \\
& New model & 0.00165 & 0.0086 & $1.662 \times 10^{-44}$ & & 0.996 & $4.80 \times 10^{-5}$ & Random \\
\hline \multirow{5}{*}{ Desorption } & Oswin & 0.0184 & 0.312 & & & 0.977 & $7.21 \times 10^{-5}$ & Random \\
& Henderson & -840.83 & 0.560 & & & 0.985 & $4.71 \times 10^{-5}$ & Random \\
& Caurie & -4.94 & 1.84 & & & 0.982 & $5.66 \times 10^{-5}$ & Random \\
& GAB & 0.01046 & 0.801 & $-6.86 \times 10^{45}$ & & 0.972 & $8.94 \times 10^{-5}$ & Random \\
& Hansen & 0.04889 & 0.244 & 1.345 & & 0.988 & $3.92 \times 10^{-5}$ & Random \\
& Peleg & 0.024 & 5.003 & 0.025 & 0.513 & 0.988 & $3.84 \times 10^{-5}$ & Random \\
& New model & 0.0027 & 0.01117 & $-4.314 \times 10^{-44}$ & & 0.989 & $3.64 \times 10^{-5}$ & Random \\
\hline
\end{tabular}


Postprint: Feng C, Janssen H, Wu C, Feng Y, Meng Q. 2013. Validating various measures to accelerate the static gravimetric sorption isotherm determination, Building and Environment, 69:64-71.

doi: 10.1016/j.buildenv.2013.08.005

\section{Figure captions}

Fig. 1 EMCs of large and small AAC samples at $25^{\circ} \mathrm{C}$

a. Adsorption process

b. Desorption process

Fig. 2 Adsorption fittings with GAB and Peleg models

Fig. 3 Residual plots of the fitting with GAB and Peleg models (adsorption) 


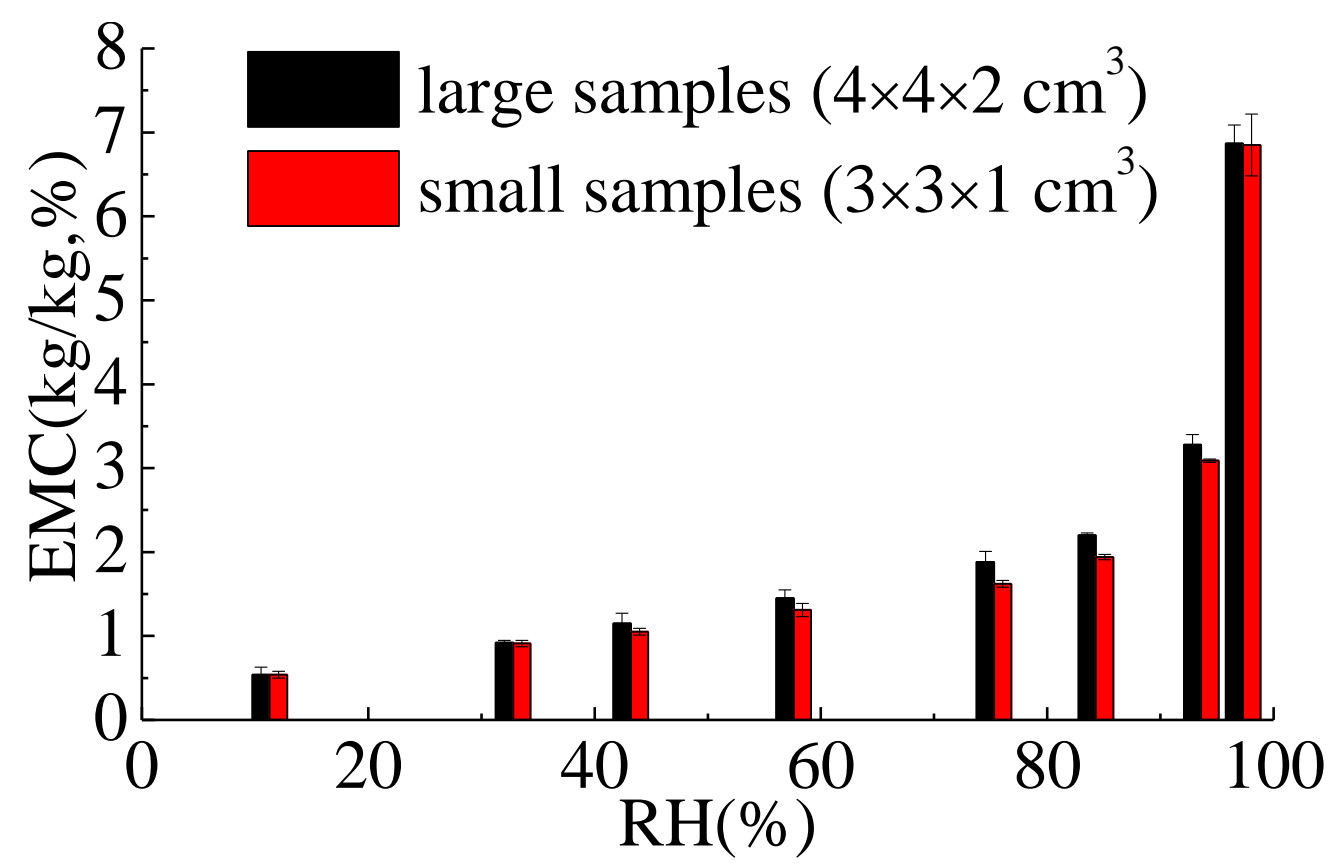

a. Adsorption process

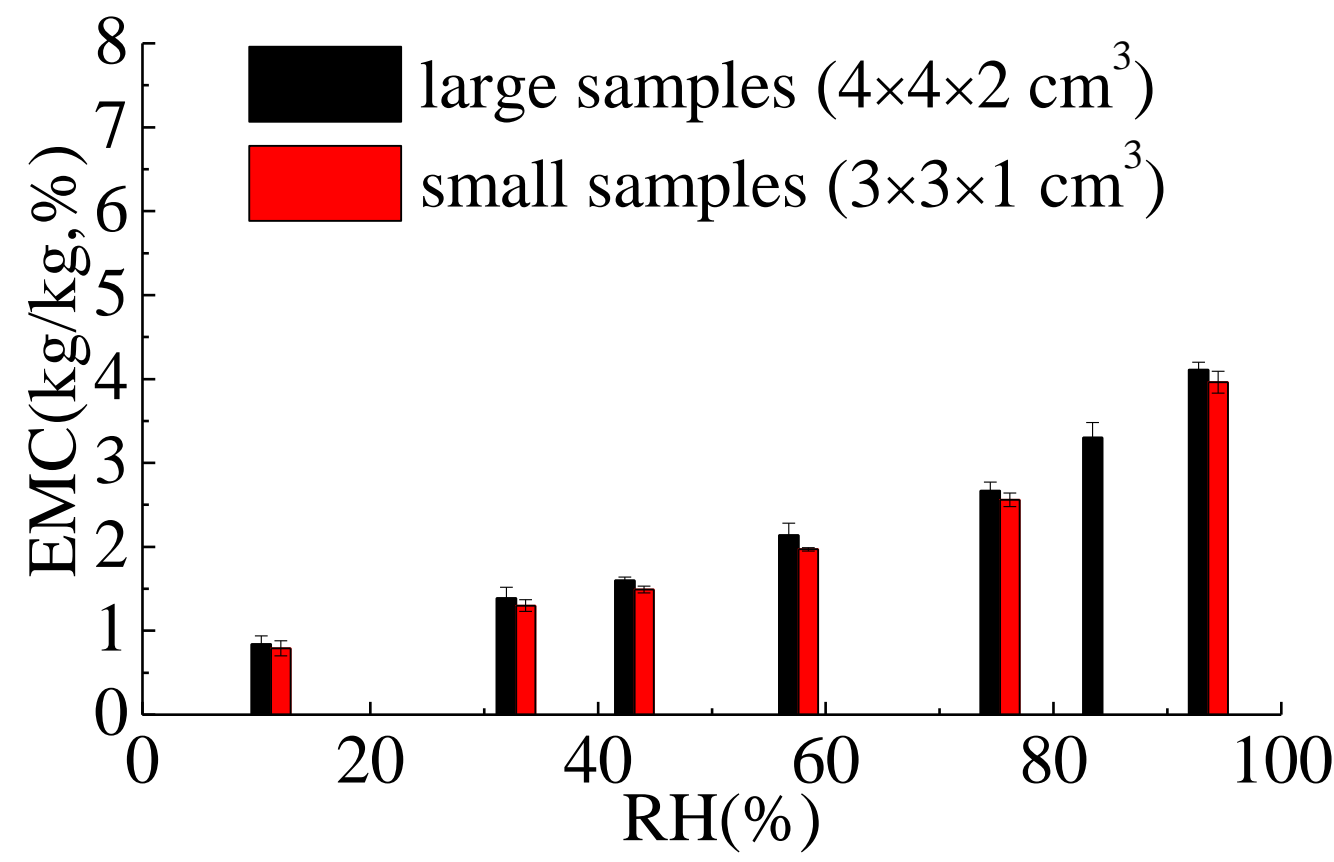

b. Desorption process

Fig. 1 EMCs of large and small AAC samples at $25^{\circ} \mathrm{C}$ 
Postprint: Feng C, Janssen H, Wu C, Feng Y, Meng Q. 2013. Validating various measures to accelerate the static gravimetric sorption isotherm determination, Building and Environment, 69:64-71.

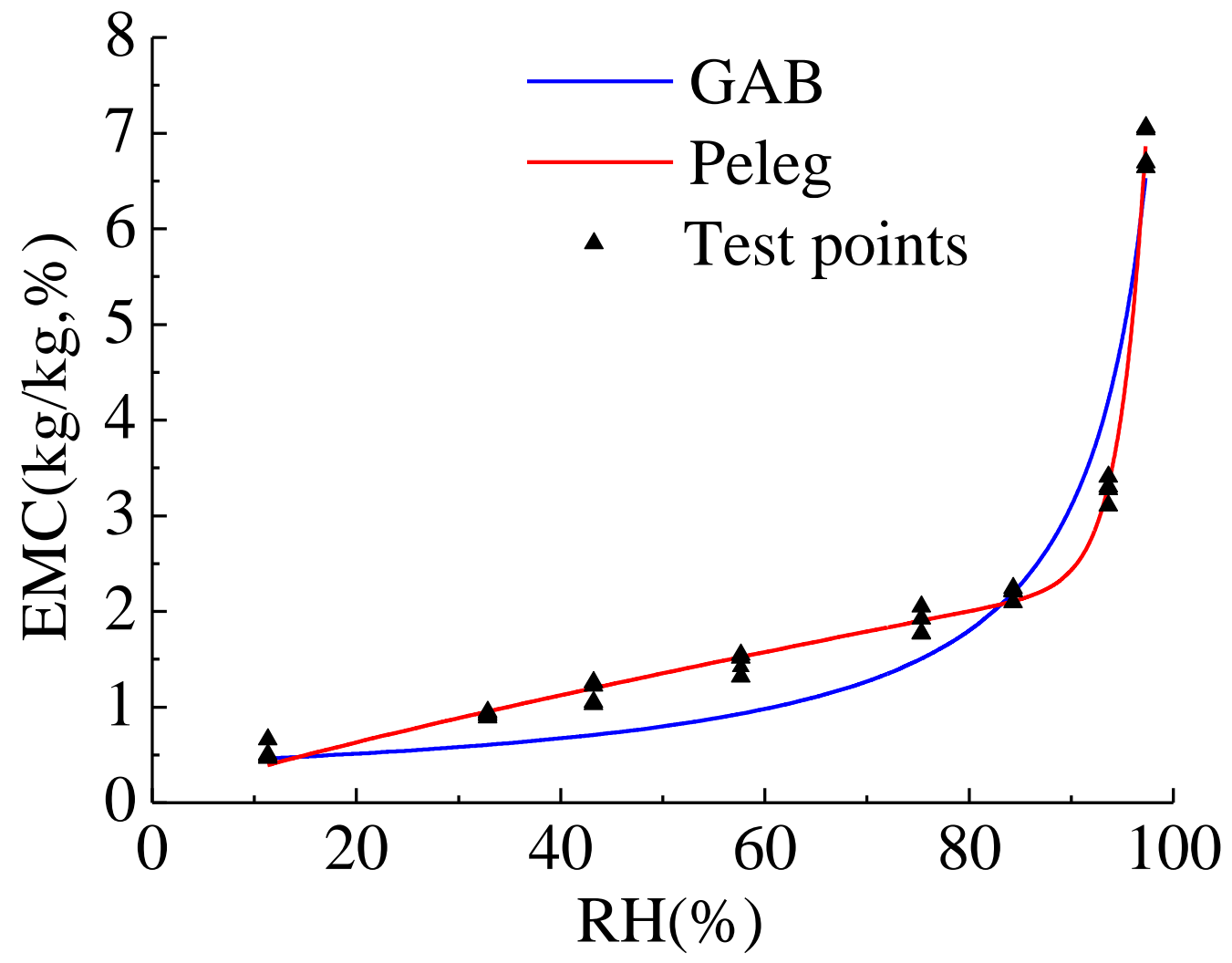

Fig. 2 Adsorption fittings with GAB and Peleg models 


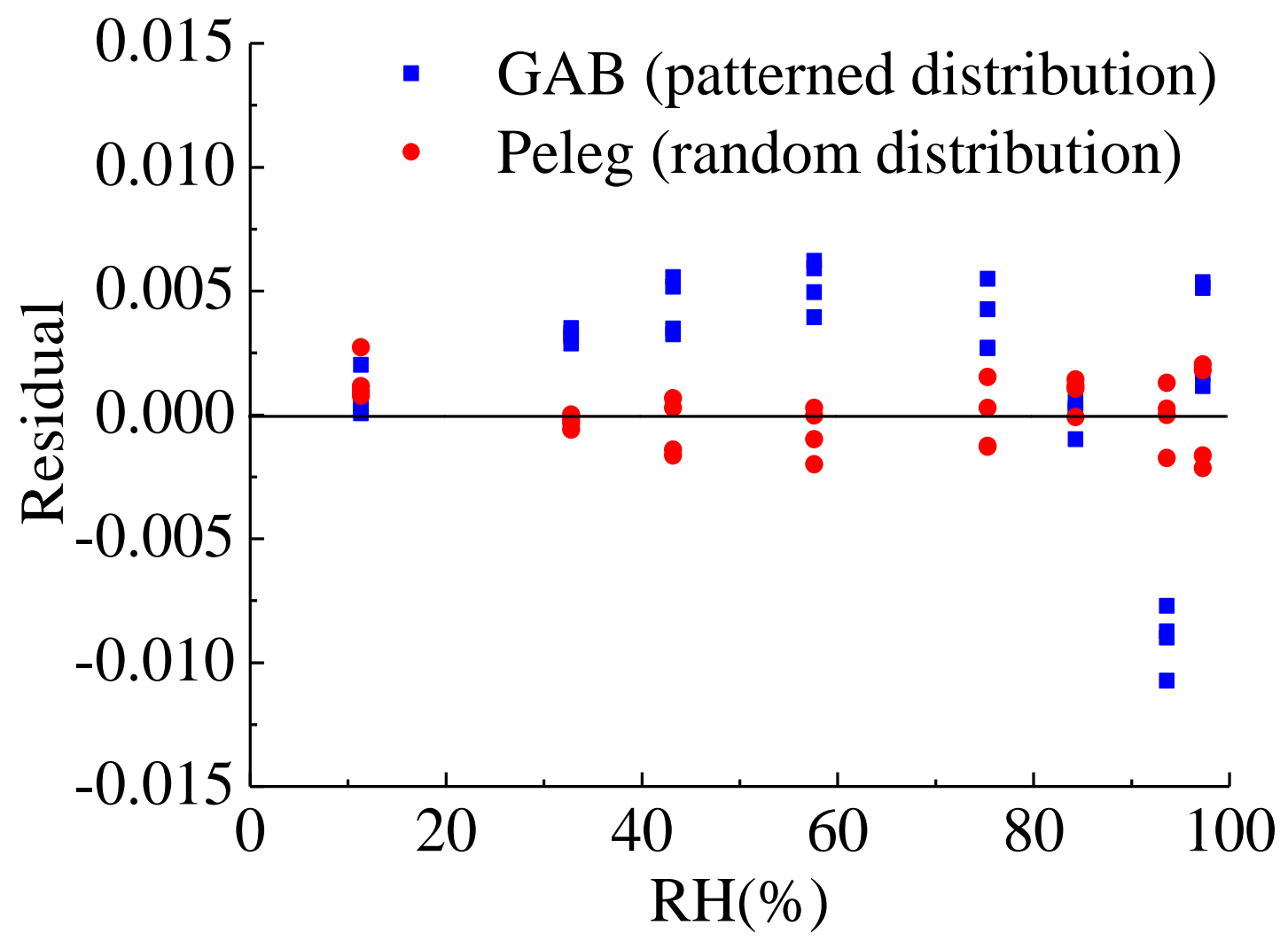

Fig. 3 Residual plots of the fitting with GAB and Peleg models (adsorption) 